Citation: Volume: 30 issue: 3, page(s): 268-276

Article first published online: March 31, 2015;Issue published: March 1, 2016

DOI: https://doi.org/10.1177/0269215515578697

\title{
Is Stroke Early Supported discharge still effective in practice? A prospective comparative study
}

\author{
Rebecca J Fisher', Christine S Cobley², Iskra Potgieter', Amy Moody', Fiona Nouri', Catherine \\ Gaynor ${ }^{4}$, Adrian Byrne ${ }^{5}$ and Marion F Walker
}

1School of Medicine, University of Nottingham, UK 2Clinical Psychology Unit, University of Sheffield, UK 3School of Health Sciences, University of Nottingham, UK 4Nottingham University Hospitals NHS Trust, UK 5School of Social Sciences, University of Manchester, UK

Abstract

Objective: Randomised controlled trials have shown the benefits of Early Supported Discharge (ESD) of stroke survivors. Our aim was to evaluate whether ESD is still beneficial when operating in the complex context of frontline healthcare provision.

Design: We conducted a cohort study with quasi experimental design. A total of 293 stroke survivors (transfer independently or with assistance of one, identified rehabilitation goals) within two naturally formed groups were recruited from two acute stroke units: 'ESD' $n=135$ and 'Non ESD' $n=158$ and 84 caregivers. The 'ESD' group accessed either of two ESD services operating in Nottinghamshire, UK. The 'Non ESD' group experienced standard practices for discharge and onward referral. Outcome measures (primary: Barthel Index) were administered at baseline, 6 weeks, 6 months and 12 months.

Results: The ESD group had a significantly shorter length of hospital stay $(P=0.029)$ and reported significantly higher levels of satisfaction with services received $(P<0.001)$. Following adjustment for age differences at baseline, participants in the ESD group $(n=71)$ had significantly higher odds (compared to the Non ESD group, $n=85$ ) of being in the $\geqslant 90$ Barthel Index category at 6 weeks (OR $=1.557,95 \% \mathrm{Cl} 2.579$ to 8.733$), 6$ months (OR $=$ $1.541,95 \% \mathrm{Cl} 2.617$ to 8.340 ) and 12 months (OR $0.837,95 \% \mathrm{Cl} 1.306$ to 4.087 ) respectively in relation to baseline. Carers of patients accessing ESD services showed significant improvement in mental health scores $(P<0.01)$.

Conclusion: The health benefits of ESD are still evident when evidence based models of these services are implemented in practice. 


\section{Introduction}

There is strong evidence for the benefits of Stroke Early Supported Discharge (ESD) services: multidisciplinary teams that co-ordinate the transfer of care from hospital to home and provide specialist rehabilitation in the early stages back at home. ${ }^{1,2}$ Meta-analyses of 14 randomised controlled trials $(n=1957)$ have shown that Early Supported Discharge reduces the risk of death and dependency and leads to improvements in patient satisfaction levels, in addition to reducing hospital stay by 8 days. ${ }^{1,2}$

On the strength of this evidence base, many countries, including England, now recommend the provision of Early Supported Discharge services in national stroke guidelines and policy documents. 3-7 What remains to be investigated however, is whether Early Supported Discharge is still beneficial when operating in the unpredictable and complex context of frontline healthcare provision. ${ }^{8}$

Here we quantitatively investigate whether Early Supported Discharge services that have adopted an evidence based model $^{9}$ do achieve what the meta-analyses suggested they would: to accelerate the return home of stroke survivors and produce equivalent or better outcomes for patients than conventional care.

\section{Methods}

Patients admitted to stroke units in Nottinghamshire, England, between November 2010 and February 2012, were screened for inclusion if they fulfilled the following eligibility criteria: ${ }^{9}$ clinical diagnosis of stroke; transfer independently or with assistance of one (i.e. mild to moderate stroke); identified rehabilitation goals, medically stable, and able and willing to sign informed consent. These criteria reflected the adopted practices of the two Early Supported Discharge services involved in this study. Stroke patients (and their carers) who were then referred to an Early Supported Discharge service, and stroke patients (and carers) who met the recommended eligibility criteria, but who did not get referred to an Early Supported Discharge service, were recruited to the study and written informed consent obtained. Researchers undertook baseline assessment within 14 days of stroke onset.

Patients within the Early Supported Discharge or 'ESD' group accessed either of two Early Supported Discharge services. Both Early Supported Discharge services had adopted an evidence based model informed by an international consensus docu-ment, ${ }^{9,10}$ providing a stroke specialist intervention that consisted of prompt, co-ordinated discharge from hospital with the immediate provision of rehabilitative care. A multidisciplinary team offering co-ordinated physician, nursing, physiotherapy, occupational therapy, speech therapy, psychological intervention and social care support provided intensive, daily, stroke specialist rehabilitation in the patient's home for up to six weeks. Onward referral to other healthcare services after the Early Supported Discharge intervention were organised as required.

The 'Non ESD' group was formed of stroke patients who met eligibility criteria but were not referred to, or were unable to access, Early Supported Discharge services. Despite receiving care in the same hospital, their home and General Practitioner were based in a postcode not covered by the Early Supported Discharge service. These patients lived in the same counties as ESD patients (Nottinghamshire or Derbyshire) and experienced standard practices for discharge planning.

Trained researchers measured outcomes at baseline and follow-up visits at 6 weeks, 6 months ( 26 weeks), and 12 months (52 weeks) post baseline assessment. The primary outcome measure was the Barthel Index, ${ }^{11}$ measuring functional independence of stroke survivors. Secondary measures were the Nottingham Extended Activities of Daily Living Scale (NEADL) ${ }^{12}$ and the General Health Questionnaire $28(\mathrm{GHQ}-28)^{13}$ to assess psychological wellbeing; Medical 
Outcomes Study Short Form-36 (SF-36) ${ }^{14}$ and the EuroQol Index (EQ5D) ${ }^{15}$ to measure quality of life. A satisfaction questionnaire (4 point likert scale) was used to assess perceived knowledge and satisfaction with information on stroke. ${ }^{16}$ Caregivers were asked to complete the GHQ-28, the SF-36 and the satisfaction questionnaire. The NEADL and carer outcomes were not included at baseline assessment. Permission was obtained from patients to access medical records stored on Hospital Trust and Primary Care Trust databases.

We aimed for a sample size of $n=110$ per group ${ }^{17,18}$ to satisfy power of $80 \%$ at $5 \%$ detection level for the primary outcome measure (effect size difference of 2-7.5 points). Group homogeneity and hospital data were analysed using t-tests for continuous variables, Chisquared tests $\left(\chi^{2}\right)$ for categorical variables and Mann-Whitney $U$ tests for skewed data. Between group differences were tested using the Mann-Whitney $U$ test, within group differences using the Friedman test and post-hoc analysis using Wilcoxon signed-rank tests with a Bonferroni correction applied.

For the Generalized Estimating Equation modelling (GEE), fitting an exchangeable working correlation matrix, the dependent variable was categorised as binary; Barthel Index score of 90 and above $(\geqslant 90)$ or below $90(<90)$, using a logit link, due to its highly skewed nature (90 was the overall median Barthel Index score). Similarly, we categorised the demographic variable of age as $<75$ and $\geqslant 75$. $^{1,2}$

The GEE analysis was performed on a subgroup of patients determined by the interquartile range of age of the whole sample, to adjust for differences at baseline. All patients including those with incomplete sets of data and repeated measures were accounted for. Any missing values at follow-up were imputed using last-value-observed carried forward. ${ }^{19}$ Regression coefficients were calculated for the effects of ESD compared to Non ESD as $\beta$ values and standard errors of either increasing or decreasing the likelihood of a participant being in either Barthel Index score category. The significance of the predictors ( $\beta$ values and standard errors) was estimated using the Wald test and the associated odds ratios were computed by taking the exponential of the $\beta$ coefficients for each regression coefficient. We undertook sensitivity analyses by varying the binary Barthel threshold values to 85, 93, 95 and 90 (median scores at each time point). All hypotheses were tested two sided, with a critical value of $<0.05$. SPSS version 20 was used for all analysis.

\section{Results}

Of the 293 participants that enrolled into the study, 258 completed the outcome assessments at 6 weeks, 237 at 6 months and 226 at 12 months (Figure 1). The 6-week assessment was completed by 84 caregivers; the 6 -month assessment by 71 caregivers; and the 12-month assessment by 64 caregivers.

The Non ESD patient group ( $n=158)$ included patients who accessed a community stroke rehabilitation team $(n=59)$ or a neurorehabilitation outpatient therapy service $(n=27)$. Patients who did not receive any services following discharge from hospital $(n=72)$ were also included in this group of participants.

Table 1 shows the demographic characteristics of the groups at baseline. The groups were similar with regard to Barthel Index scores, ethnicity and sex variables and number of days between stroke onset and baseline assessment. The ESD group were, on average, slightly younger than the Non ESD group.

We found no significant differences between groups in mortality or number of readmissions to a stroke unit or general ward within 28 days or within 1 year of baseline assessment (Table 2). Patients referred to ESD had a significantly shorter average stay on hospital rehabilitation wards (0 
days versus 6.5 days; $P=0.018$ ) and a shorter total length of hospital stay ( 9 days versus 11 days; $P=0.029)$.

Between group comparisons of outcome measure data showed no significant differences between groups when compared at each individual time point. Analysis of questionnaire data (4 point likert scale, [median and interquartile range figures reported]) did however show that, at 6 weeks, the ESD group reported a significantly higher of level of overall satisfaction with services [ESD 3(2-3), Non ESD 2(2-3) $P<0.001$ ], and more knowledge of reducing the risk of stroke [ESD 3(1-3), Non ESD 2(1-3) $P<0.01$ ], practical help [ESD 2(1-3), Non ESD 1(0-3) $P=0.01$ ] and community services [ESD 3(23), Non ESD 2(1-3) $P<0.001]$.The ESD group also reported more knowledge of emotional support at 12 months [ESD 1(0-3), Non ESD 0(0-1) $P<0.001]$. Both ESD and Non ESD patients improved significantly over time (Table 3). For the non ESD group there was also a significant increase over time on the NEADL $(P=0.037)$ and for the ESD group only, there were significant increases in quality of life as measured by the EuroQol Index $(P=0.001)$ and the physical subcomponent summary scores (PSC) of the SF36 ( $P=0.01)$. To further explore changes over time in a nonparametric repeated measures analysis, GEE modeling was conducted using the primary outcome measure, the Barthel Index, as the dependent variable Median (interquartile range in parentheses). Q: measure not administered at time point, BI: Barthel Index, PCS: Physical Component Summary Measure of SF36, MCS: Mental Health Component Summary Measure of SF36. Groups were compared using Friedman Test. *Significant at $P<0.05$.

(Table 4). To adjust for significant differences in age between groups at baseline, a sample of the main cohort, determined by the interquartile age range (63-81) of the whole data set, was selected for analysis. Exploring combined within and between group effects, the interaction model (adjusted for covari-ates) showed that ESD group participants had significantly higher odds of being in the $\geqslant 90$ Barthel category at 6 weeks, 6 months and 12 months respectively in relation to baseline. Results remained consistent when different threshold values were investigated in sensitivity analysis, demonstrating the robustness of the model.

Between group comparisons showed no significant differences between carers in ESD and Non ESD groups with regards to caregivers' physical, mental and psychological wellbeing, and satisfaction and knowledge with stroke related services. There was a statistically significant improvement in mental health (SF-36 MCS; Table 5) over time in carers of patients that received ESD services $\left(\chi^{2}(2)=13.000, P=0.002\right)$. Post-hoc analysis showed a statistically significant improvement in mental health scores at 6 weeks and 6 months, compared to baseline in the ESD cohort of carers $(Z=-3.646, P<0.001)$.

\section{Discussion}

We have shown that when adopting an evidence based model, Early Supported Discharge services can significantly reduce length of hospital stay and result in equivalent or better outcomes for mild to moderate stroke patients and their carers - benefits that were suggested by clinical trial data. ${ }^{1,2}$ We have also presented quantitative methodology that can be used when evaluating the effectiveness of evidence based innovations, such as Early Supported Discharge, outside of a randomised controlled trial setting. ${ }^{20}$

Our principal finding was that Early Supported Discharge accelerated the recovery of mild to moderate stroke survivors, as measured by activities of daily living and the Barthel Index, over a one year period. That patients in the Non ESD group also showed recovery over time is perhaps not surprising, given that many of them accessed other rehabilitative care via in-hospital or via outpatient services. What is important is that ESD patients showed a steeper recovery trajectory. A 
methodological issue worth noting is that this was only brought to light by modeling changes over time (interaction effects) and adjusting for covariates. This would have been overlooked by the use of static, between group, analyses at each time point only (which resulted in a lack of main effect of group in the GEE modelling).

Whereas both ESD and Non ESD patients showed significant improvements over time in secondary outcome measures of general health and quality of life, at the 6 week follow up point, ESD

patients were significantly more satisfied with services and had increased knowledge of risk, practical help and community services. In addition, carers of patients accessing Early

Supported Discharge services showed significant improvements over time in the mental health component of the SF-36. This goes some way to negate earlier fears that ESD may have a negative impact on carers.1,2,9,21

In addition to these benefits, patients in the ESD group had a significantly shorter time in hospital compared to Non ESD patients, the latter spending significantly more time on rehabilitation wards. That this was only a difference of 2 days (compared to the 8 days referred to in previous meta-analyses), could be explained by the overall reduction in length of hospital stay of all stroke patients since the original randomised controlled trials were conducted and the fact that the Non ESD group did have access to further rehabilitation services other than ESD at discharge.

Reduction in length of hospital stay originally made Early Supported Discharge attractive from an economic perspective. The idea that Early Supported Discharge services could be funded entirely by a reduction in length of hospital stay, we suggest, is overly optimistic. Cost savings from a reduction in length of hospital stay also need to be realised within the funding arrangements associated with healthcare provision in that country - and 'tariff' unbundling in the UK has proved problematic.

A limitation of this study is that not all patients, accessing the two Early Supported Discharge services we studied, were recruited to this study. There was a slower stream of patients (not involved in this study) who took longer (than the 14-days post stroke recruitment window used) to reach eligibility criteria for the two services. Whilst our results highlight the benefits of 'early' Early Supported Discharge to a cohort of mild to moderate patients, whether such benefits are evident for patients who accessed the service later post-stroke remains to be investigated.

Another limitation of this study was its quasi experimental nature. It was important that patients in the Non ESD group did not differ systematically from those in the ESD group. Eligibility criteria used by researchers to recruit patients to this study (and in particular to the Non ESD group) needed to be the same as criteria adopted by the two Early Supported Discharge services in practice. Groups did end up differing significantly in age, although we adjusted for this in our statistical modeling. Also, patients in the Non ESD group lived in a postcode not served by the ESD services included in the study. Whilst we are confident that both ESD and Non ESD cohorts were representative of the Nottinghamshire and Derbyshire population served by the acute hospitals involved in this study, there may have been other demographic differences between the groups that were not measured.

Lastly there is the question of whether findings are transferrable. The critical factor is that both services in this study adopted a service model informed by an international Early Supported Discharge consensus document. ${ }^{9,10}$ We suggest that because these services have adopted core components of an evidenced base service, the benefits of Early Supported Discharge were realised.

This study builds on an already strong evidence base demonstrating the benefits of Early Supported Discharge services for stroke survivors both in terms of reducing length of hospital stay and accelerating recovery at home. This, in addition to the wealth of policy and national guideline recommendations, makes it hard to understand why Early Supported Discharge services are not accessible to all eligible patients both in the UK and abroad. 


\section{Clinical message}

- Patients who received care from an evidence based Early Support Discharge service, gained the benefits anticipated from randomised controlled trials, when compared with patients who did not access the service.

\section{Conflict of interest}

The authors declare that there is no conflict of interest. Funding

This research was funded by the National Institute for Health Research Collaboration for Leadership in Applied Health Research and Care for Nottinghamshire, Derbyshire and Lincolnshire (NIHR CLAHRC NDL). 


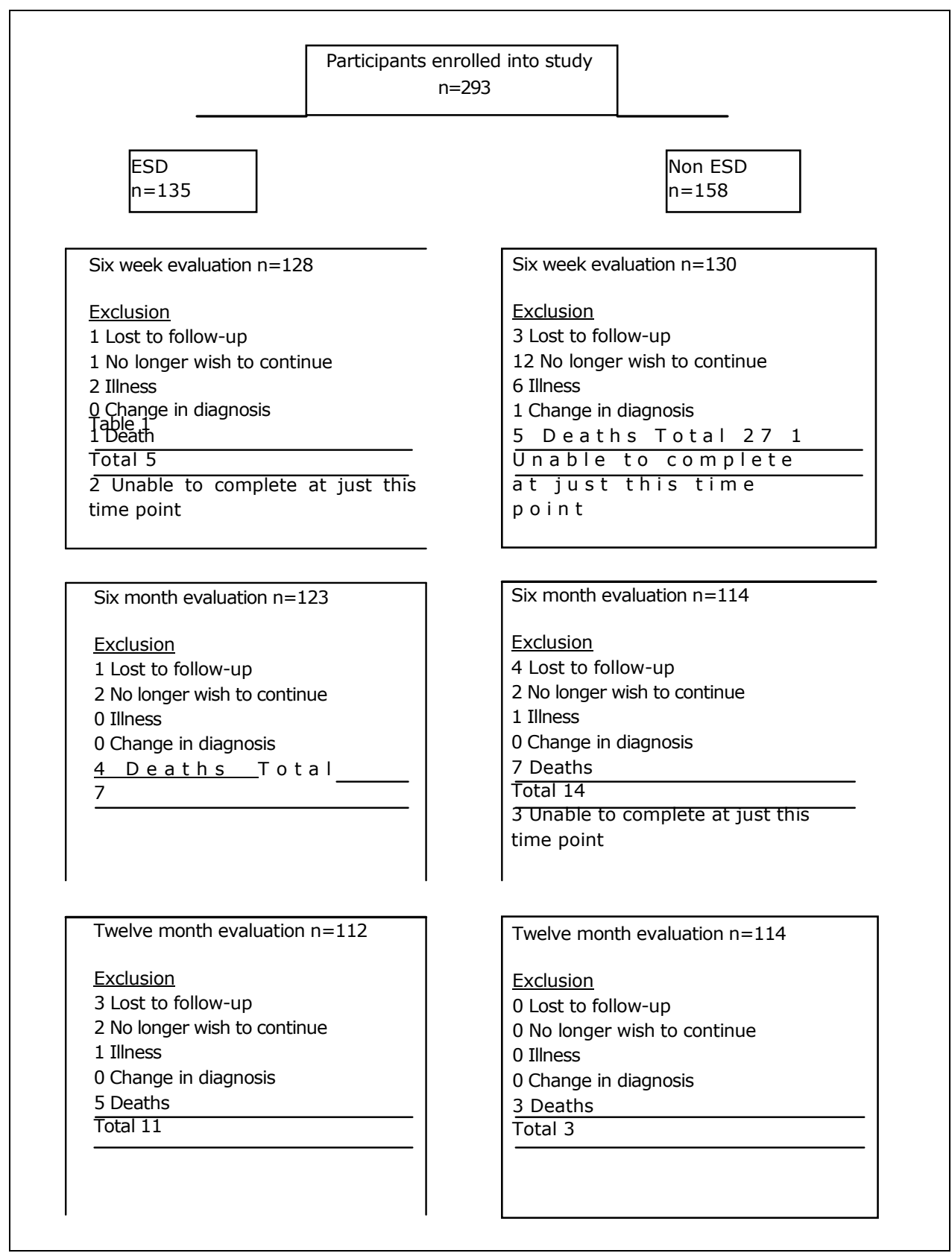

Figure 1. Flow of participants through study. 
Table 1. Baseline characteristics of participants.

\begin{tabular}{|c|c|c|c|}
\hline Variable & $\operatorname{ESD}(n=135)$ & Non ESD $(n=158)$ & $P$ value \\
\hline $\begin{array}{l}\text { Age, median (IQR) }+\dagger+ \\
\mathrm{N} \text { days between stroke } \\
\text { onset and baseline } \\
\text { assessment, mean (SD) }\end{array}$ & $\begin{array}{l}71(62-79) \\
7(7)\end{array}$ & $\begin{array}{l}76(65.75-82) \\
6(6)\end{array}$ & $\begin{array}{l}0.005^{*} \\
0.503\end{array}$ \\
\hline \multicolumn{4}{|l|}{ Gender ${ }^{\dagger}$} \\
\hline $\begin{array}{l}\text { Women, } n(\%) \\
\text { Male, } n(\%)\end{array}$ & $\begin{array}{l}45(33.3 \%) \\
90(66.6 \%)\end{array}$ & $\begin{array}{l}56(35.4 \%) \\
102(64.6 \%)\end{array}$ & 0.705 \\
\hline $\begin{array}{l}\text { Baseline BI, median (IQR) } \\
\text { ††† }\end{array}$ & $80(65-95)$ & $85(70-95)$ & 0.174 \\
\hline \multicolumn{4}{|l|}{ Ethnicity ${ }^{\dagger}$} \\
\hline White, $n$ (\%) & $127(94 \%)$ & 155 (98.1\%) & 0.068 \\
\hline Other, $n(\%)$ & $8(6 \%)$ & 3 (1.9\%) & \\
\hline
\end{tabular}

†Groups were compared using $\chi^{2}$ for ethnicity and gender. + tGroups were compared using t-test for $\mathrm{N}$ days between stroke onset and baseline assessment. $+++G$ roups were compared using Mann Whitney $U$ Test for age and baseline Barthel score. *Significant at $P<0.05$.

Table 2. Clinical hospital data.

\begin{tabular}{|c|c|c|c|}
\hline Variable & $\operatorname{ESD}(n=135)$ & Non ESD $(n=158)$ & $P$ value \\
\hline $\begin{array}{l}\text { Total LOS acute, median }+\dagger+ \\
\text { (IQR) }\end{array}$ & $4(2-7)$ & $3(2-5.8)$ & 0.061 \\
\hline $\begin{array}{l}\text { Total LOS rehab, median } \\
\text { (IQR) +++ }\end{array}$ & $0(0-12)$ & $6.5(0-15.8)$ & $0.018^{*}$ \\
\hline $\begin{array}{l}\text { Total LOS (rehab + } \\
\text { acute stay), median }\end{array}$ & $9(4-18.3)$ & $11(5-21.0)$ & $0.029 *$ \\
\hline $\begin{array}{l}\text { Readmitted to SU within } \\
28 \text { days hospital } \\
\text { discharge, } n(\%)^{\dagger}\end{array}$ & $2(1.5 \%)$ & $1(0.7 \%)$ & 0.606 \\
\hline $\begin{array}{l}\text { Readmitted to Gen } \\
\text { ward within } 28 \text { days of } \\
\text { hospital discharge, } n\end{array}$ & $12(9.2 \%)$ & $11(7.7 \%)$ & 0.669 \\
\hline $\begin{array}{l}\text { Readmitted to SU within } \\
1 \text { year baseline } \\
\text { assessment, } n(\%)^{\dagger}\end{array}$ & $18(13.8 \%)$ & $10(7.0 \%)$ & 0.073 \\
\hline $\begin{array}{l}\text { Readmitted to Gen } \\
\text { ward within } 1 \text { year } \\
\text { baseline assessment, } n\end{array}$ & 47 (36.0\%) & $62(43.4 \%)$ & 0.266 \\
\hline Case fatality, $n(\%) \dagger$ & $11(8.5 \%)$ & $16(11.2 \%)$ & 0.544 \\
\hline
\end{tabular}

†Groups were compared using $\chi^{2}$ for readmissions and case fatality. $+++G$ roups were compared using Mann Whitney $U$ Test for length of hospital stay.

*Significant at $P<0.05$. Figures provided rounded to one decimal place. 
Table 3. Comparison of patient outcomes: Within group comparison.

\begin{tabular}{|c|c|c|c|c|c|c|c|}
\hline Group & Variable & $n$ & Baseline & 6 Weeks & 6 Months & 12 Months & $P$ \\
\hline \multirow[t]{7}{*}{ ESD } & BI & 110 & $80(65-91)$ & $95(84-100)$ & $95(80-100)$ & $90(75-100)$ & $0.000 *$ \\
\hline & NEADL & 110 & $\mathrm{Q}$ & $35(24-49)$ & $39(27-50)$ & $31.5(18-46)$ & 0.146 \\
\hline & GHQ-28 & 108 & $25(18-35)$ & $22(16-34)$ & 19(12-30) & $18.5(13-29)$ & $0.000^{*}$ \\
\hline & SF36-PCS & 108 & $32.9(24.3-39.9)$ & $32.4(25.4-42.4)$ & $33.9(22.9-47.1)$ & $31.7(21.3-43.1)$ & $0.010 *$ \\
\hline & SF36-MCS & 108 & $50.3(38.8-58.7)$ & $47.1(35.7-55.3)$ & $52.4(43.9-58.1)$ & $53.3(44.2-60.2)$ & $0.000 *$ \\
\hline & $\begin{array}{l}\text { EuroQol } \\
\text { Index }\end{array}$ & 110 & $0.74(0.65-0.84)$ & $0.78(0.7-0.88)$ & $0.77(0.68-1.00)$ & $0.77(0.65-0.88)$ & $0.001 *$ \\
\hline & $\begin{array}{l}\text { EuroQol } \\
\text { Imaginable } \\
\text { Health }\end{array}$ & 110 & $55(45-70)$ & $60(50-80)$ & $65(50-80)$ & $70(50-80)$ & $0.000 *$ \\
\hline \multirow[t]{7}{*}{ NonESD } & BI & 109 & $85(70-95)$ & $90(80-100)$ & $95(80-100)$ & $95(75-100)$ & $0.000 *$ \\
\hline & NEADL & 109 & $\mathrm{Q}$ & $35(24-52)$ & $36(24.5-54)$ & $36(20-50.5)$ & $0.037^{*}$ \\
\hline & GHQ-28 & 108 & $23(17-31)$ & $22(16-29)$ & $19.5(14-25)$ & $20(13-26)$ & $0.001 *$ \\
\hline & SF36-PCS & 108 & $35.1(28.3-43.3)$ & $34.5(26.3-42.9)$ & $33.3(24.8-43.9)$ & $35.3(24.1-45.8)$ & 0.413 \\
\hline & SF36-MCS & 108 & $51.3(43.6-58.0)$ & $47.9(34.4-57.1)$ & $54.1(45.8-58.5)$ & $53.5(48.1-59.1)$ & $0.006^{*}$ \\
\hline & $\begin{array}{l}\text { EuroQol } \\
\text { Index }\end{array}$ & 110 & $0.75(0.68-0.88)$ & $0.77(0.69-0.88)$ & $0.77(0.68-0.88)$ & $0.77(0.69-0.88)$ & 0.711 \\
\hline & $\begin{array}{l}\text { EuroQol } \\
\text { Imaginable } \\
\text { Health }\end{array}$ & 110 & $60(50-80)$ & $65(50-80)$ & $70(50-80)$ & $75(50-85)$ & $0.002 *$ \\
\hline
\end{tabular}


Table 4. Generalized estimating equation modelling: Barthel Index scores at $6(n=139), 26(n=133)$ and 52 $(n=127)$ weeks using baseline $(n=156)$ as point of reference.

\begin{tabular}{|c|c|c|c|c|c|c|}
\hline & Parameter & $\beta$ & Std. Error & OR & $95 \% \mathrm{Cl}$ & $P$ value \\
\hline \multicolumn{7}{|l|}{$\begin{array}{l}\text { Model A: } \\
\text { main effects }\end{array}$} \\
\hline & Gender & 0.155 & 0.2734 & 1.167 & $0.683-1.995$ & 0.572 \\
\hline & Ethnicity & 0.054 & 0.6855 & 1.055 & $0.275-4.044$ & 0.938 \\
\hline & Age & -0.259 & 0.2607 & 0.772 & $0.463-1.287$ & 0.321 \\
\hline & Group & -0.208 & 0.2663 & 0.812 & $0.482-1.369$ & 0.436 \\
\hline & Time6Weeks & 1.154 & 1.936 & 3.172 & $2.170-4.636$ & $0.000 *$ \\
\hline & Time26Weeks & 1.103 & 0.2048 & 3.013 & $2.017-4.500$ & $0.000 *$ \\
\hline & Time52Weeks & 0.793 & 0.2067 & 2.210 & $1.474-3.314$ & $0.000 *$ \\
\hline \multirow{6}{*}{$\begin{array}{l}\text { Model B: } \\
\text { interaction } \\
\text { effects }\end{array}$} & Group*Gender & 0.011 & 0.3606 & 1.011 & $0.499-2.050$ & 0.975 \\
\hline & $\begin{array}{l}\text { Group } \\
\text { *Ethnici }\end{array}$ & -0.941 & 0.3969 & 0.390 & $0.179-0.850$ & $0.018^{*}$ \\
\hline & Group *Age & -0.246 & 0.4111 & 0.782 & $0.349-1.750$ & 0.550 \\
\hline & $\begin{array}{l}\text { Group } \\
\text { *Time6Weeks }\end{array}$ & 1.557 & 0.3112 & 4.745 & $2.579-8.733$ & $0.000 *$ \\
\hline & $\begin{array}{l}\text { Group } \\
\text { *Time26Weeks }\end{array}$ & 1.541 & 0.2957 & 4.671 & $2.617-8.340$ & $0.000 *$ \\
\hline & $\begin{array}{l}\text { Group } \\
\text { *Time52Weeks }\end{array}$ & 0.837 & 0.2910 & 2.311 & $1.306-4.087$ & $0.004 *$ \\
\hline
\end{tabular}

*Significant at $P<0.05$.

Table 5. Comparison of carer outcomes: Within group comparison.

\begin{tabular}{llllccl}
\hline Group & Variable & $n$ & 6 Weeks & 6 Months & 12 Months & $P$ \\
\hline ESD & GHQ-28 & 26 & $18.5(14.5-27)$ & $17(14.75-20.5)$ & $19.5(11.75-26.25)$ & 0.512 \\
& SF36-PCS & 26 & $47.2(35.7-$ & $46.2(35.9-55.9)$ & $44.8(35.9-55.9)$ & 0.341 \\
\multirow{3}{*}{ NonESD } & SF36-MCS & 26 & $44.6(37.8-$ & $54(50-57.4)$ & $51.1(44 .-56.7)$ & $0.002 *$ \\
& GHQ-28 & 26 & $15.5(12-26)$ & $19(13-30.25)$ & $15.5(11.5-31)$ & 0.282 \\
& SF36-PCS & 26 & $48.3(36.3-$ & $48.3(36.3-55.7)$ & $46.8(36.2-55.3)$ & 0.060 \\
& SF36-MCS & 26 & $46.1(34.8-$ & $50.8(37.3-57.9)$ & $52.6(41.0-57.1)$ & 0.076 \\
\hline
\end{tabular}

Median (interquartile range in parentheses). Groups were compared using Friedman Test. *Significant at $P<0.05$. 


\section{References}

1. Langhorne P (for the Early Supported Discharge Trialists). Services for reducing duration of hospital care for acute stroke patients. Cochrane database of systematic reviews 2005, issue 2.

2. Fearon $\mathrm{P}$ and Langhorne P. Services for reducing duration of hospital care for acute stroke patients. Cochrane database of systematic reviews 2012, Issue 9.

3. Duncan PW, Zorowitz R, Bates B, Choi JY, Glasberg JJ, Graham GD, et al. Management of adult stroke rehabilitation care: A clinical practice guideline. Stroke, 2005;36:100-143.

4. National Stroke Foundation. Clinical guidelines for stroke rehabilitation and recovery. Melbourne: Australian Government and National Health and Medical Research Council, 2005.

5. Department of Health. National stroke strategy. Available at: http://www.dh.gov.uk/en/Publicationsandstatistics/ Publications/PublicationsPolicyAndGuidance/DH_081062. 2007.

6. Heart Stroke Foundation of Ontario. Consensus panel on the stroke rehabilitation system "time is function". Available at: http://www.heartandstroke.on.ca. 2007.

7. Intercollegiate Stroke Working Party. National clinical guideline for stroke, fourth edition. London: Royal College of Physicians, 2012.

8. Walker MF, Fisher RJ, Korner-Bitensky N, McCluskey A and Carey L. From what we know to what we do: Translating Stroke Rehabilitation Research into Practice. International Journal of Stroke, 2013;8:11-17.

9. Fisher RJ, Gaynor C, Kerr M, Langhorne P, Anderson C, Bautz-Holter E, et al. A consensus on stroke: Early supported discharge. Stroke. 2011;42:1392-1397.

10. Chouliara N, Fisher RJ, Kerr M and Walker MF. Implementing evidence-based Stroke Early Supported Discharge services: a qualitative study of challenges, facilitators and impact. Clinical Rehabilitation. 2014;28(4): 370-377.

11. Mahoney FI and Barthel DW. Functional evaluation: the Barthel Index. Maryland State Medical Journal. $1965 ; 14: 61-65$.

12. Nouri FM and Lincoln NB. An extended activities of daily living scale for stroke patients. Clinical Rehabilitation. 1987; 1:301-305.

13. Goldberg DP and Hillier VE. A scaled version of the general health questionnaire. Psychological Medicine. 1979; 9:139-145.

14. Ware JE. SF-36 Physical and mental health summary scales: a users manual. Boston Mass: The Health Institute, New England Medical Center, 1994.

15. Williams A. EuroQol-a new facility for the measurement of health-related quality of life. The EuroQol Group - Health Policy, 1990.

16. Lincoln NB, Francis VM, Lilley SA, Sharma JC and Summerfield M. Evaluation of a Stroke Family Support Organiser: A Randomized Controlled Trial. Stroke. 2003;34:116-121.

17. Mayo NE, Wood-Dauphinee S, Côté R, Gayton D, Carlton J, Buttery J and Tamblyn R. There's no place like home. An evaluation of early supported discharge for stroke. Stroke. 2000; 31: 1016-1023.

18. Donnelly $\mathrm{M}$, Power $\mathrm{M}$, Russell $\mathrm{M}$ and Fullerton $\mathrm{K}$. Randomized controlled trial of an early discharge rehabilitation service. The Belfast community stroke trial. Stroke. 2004; 35:127-133.

19. Blankers M, Koeter MWJ and Schippers GM. Missing Data Approaches in eHealth Research: Simulation Study and a Tutorial for Nonmathematically Inclined Researchers. Journal of Medical Internet Research. 2010; 12:e54.

20. Nallamothu BK, Hayward R A and Bates ER. Beyond the randomized clinical trial. The role of effectiveness studies in evaluating cardiovascular therapies. Circulation. 2008;118:1294-1303.ingle J, Hendry C and McLafferty E. A review of the early discharge experiences of stroke survivors and their carers. Journal of Clinical Nursing. 2008;17:2384-2397. 